\title{
Presencia de un ayllu de camanchacas en el puerto de Iquique en el siglo XVII ${ }^{1}$
}

\author{
Horacio Larraín B. ${ }^{2}$ y Víctor Bugueño G. ${ }^{2}$
}

\begin{abstract}
RESUMEN
Este estudio etnohistórico se centra en el análisis de referencias documentales provenientes de Libros de la Parroquia de San Lorenzo de Tarapacá, de fines del siglo XVII. Entre los años 1686 y 1690 se nombra la existencia de un ayllo de indígenas camanchacas, pescadores y colectores de guano en la isla de Ique-ique (Iquique). Se discuten y analizan las razones que pudo tener el sacerdote visitante del puerto para denominar a la comunidad de pescadores asentada en la isla del guano como un ayllo. Se hace referencia a las razones de índole religiosa y pastoral que obligaban al sacerdote a bautizar a los recién nacidos y a estampar la respectiva Partida de Bautismo. Se sugiere que la mayoría de los apellidos indígenas que aparecen en el registro serían de una etnia diferente a la aymara (o quechua), tal vez de una antigua población de pescadores. La comunidad probablemente no se autodefinía como ayllo, sino que tal denominación le habría sido conferida por el sacerdote, dada la similitud de organización con los ayllus existentes en las aldeas agrícolas o estancias del interior o del altiplano. En todo caso, sería esta la primera mención a un ayllu de camanchacas en el extremo norte de Chile.
\end{abstract}

Palabras claves: Camanchacas, ayllu, parcialidades indígenas, etnohistoria del Norte de Chile, isla de Iquique.

\begin{abstract}
The present ethnohistorical study analyses documentary references obtained from ecclesiastic books from the late $17^{\text {th }}$ century, which belong to the Parish of San Lorenzo de Tarapaca. Between 1686 and 1699 the presence of an indigenous camanchaca ayllu is mentioned. They were mostly fishermen and guano collectors at the Ique-ique island (Iquique). The reasons that the visiting priest of the port could have to denominate the community of fisherman settled on the island of the guano as an ayllu are discussed and analysed. Priests were requested by Church authorities to baptise and write down the respective baptismal annotation of the recent born children at the moment of their periodical visits. It is here suggested that the majority of the Indian surnames quoted in text would belong to an ethnic group different from aimara, maybe from an old fishermen population. The community itself, probably did not defined themselves as ayllu, but such denomination was probably used by the local priests, due to the strong social organisational similarity with already existing inland or highland agricultural or pastoral hamlets [estancias]. In any case, this document offers us the first mention referring to a camanchaca ayllu in the history of extreme Northern Chile.
\end{abstract}

Key words: Camanchacas, ayllu, indigenous communities, ethnohistory of Northern Chile, Iquique.

\footnotetext{
1 Este trabajo se dedica con especial afecto al recuerdo del Dr. John M. Murra, a quien los autores tuvieran la fortuna de conocer y tratar personalmente en Arica el año 1972. En efecto, recién incorporado el suscrito (H. Larraín) al Departamento de Arqueología de la entonces Universidad del Norte, Sede Arica (hoy Universidad de Tarapacá), los autores tuvieron la grata oportunidad de dialogar por varios días con el Dr. Murra sobre sus inquietudes y proyectos etnohistóricos. El Dr. Murra buscaba colaboradores para su proyecto de comprobación de su hipótesis sobre la existencia de la utilización por parte de las comunidades altoandinas de un sistema interconectado de múltiples nichos ecológicos que eran explotados sucesivamente desde tempranos tiempos, desde la costa a la sierra y al altiplano. Se recuerdo el énfasis que supo poner en su explicación a los aportes de la documentación etnohistórica colonial temprana que venía de estudiar
}

y que para él era plenamente comprobatoria de esta utilización de "varios pisos ecológicos", situados a distintas altitudes y en distintos ecosistemas biológicos por parte de las comunidades altoandinas. Se reconoce que este contacto temprano con el Dr. Murra ha marcado a los autores para toda la vida en la medida en que, siguiendo sus sabios consejos, se empezó a rastrear en la documentación colonial de viajeros extranjeros o funcionarios españoles, noticias acerca del modo de vida y población de los grupos indígenas, ocupantes de la I y II Región de Chile, tema que ha sido recurrente en las investigaciones de los autores hasta el día de hoy. Artículo recibido el 13 de junio de 2010, aceptado el 11 de octubre de 2011 y corregido el 15 de octubre de 2011.

2 Centro del Desierto de Atacama, Pontificia Universidad Católica de Chile (Chile). E-mail: horaciolarrain@vtr.net; victor.tarapaca@gmail.com 
"En este trecho de tierra hay algunas caletillas con poca agua salobre donde se han recogido y huido algunos indios pescadores, pobres y casi desnudos; los vestidos son de pieles de lobos marinos y en muchas partes de esta costa beben sangre de estos lobos a falta de agua; no alcanzan un grano de maíz, no lo tienen; sus comidas solo es pescado y marisco. Llaman a estos indios Camanchacas, porque los rostros y cueros de sus cuerpos se les han vuelto como una costra colorada, durísimos; dicen les proviene de la sangre que beben de los lobos marinos, y por este color son conocidísimos" (Fray Reginaldo de Lizarraga (1605), 1968).

El tema de la presencia de indígenas pescadores-recolectores costeros, a los que tempranamente los cronistas denominaron camanchacas o changos, ha sido un tema bastante recurrente en la literatura etnohistórica sur-peruana y chilena. El tema interesó ya a Ricardo Latcham (1910) y a Max Uhle (1959), especialmente en su obra final Wesen und Ordnung der altperuanischen Kulturen. Los trabajos de J. M. Camacho (1943) en Bolivia, de M. Rostworowski en Perú (1974, 1981a, 1981b, 1986) y los de J. M. Casassas, (1974), B. Bittmann (1974; 1984a; 1984b; 1986), Juan Herrera Veas (1997), V. Castro (2001), J. Hidalgo (2004) y G. Galdós (1982), publicados en Chile, han contribuido a iluminar paulatinamente tanto sus aspectos culturales y demográficos, como su filiación étnica y su caracterización económica. Se ha discutido ampliamente si constituyeron una etnia particular, dotada de lengua y cultura propia, o solo era una denominación nacida de su modus vivendi peculiar, reflejado en rasgos propios y distintivos, con notable adaptación al ecosistema marino. Los autores se interesaron por el tema en su tesis de Maestría en Antropología Social, para arrojar algo de luz sobre la densidad de su población y su localización geográfica en la costa norte chilena, a través de la documentación etnohistórica por entonces accesible (Larraín, 1978-79). Poco después, han tratado de ahondar en su identidad cultural, examinando sus modos de vida a través de sus rasgos ecoculturales (Larraín, 1978-79). Por fin, en la obra sobre la Etnogeografía de Chile, han analizado sus características ecoculturales y demográficas (Larraín, 1984), sugiriendo que esta etnia ocupa una zona biogeográfica totalmente peculiar y propia, denominada zona ecocultural 2, y que se caracteriza por un clima de nieblas abundantes y una biogeografía endémica pero raquítica, ceñida estrictamente al área de los oasis de niebla (Larraín, 1987). Estos trabajos tienen un enfoque ecológico-cultural, tratando de mostrar siempre la relación de sus patrones culturales con el sustrato geográfico-ecológico, en una perspectiva que se ha denominado ecoantropológica.

El historiador José María Casassas (1974) había sostenido que habrían existido tres grupos diferentes de pescadores-recolectores marinos: camanchacas, changos y proanches, de acuerdo a las denominaciones presumiblemente étnicas encontradas por él en el Libro de varias Ojas del Curato de Chiuchíu. Más aún, avanzó la hipótesis de una diferente y peculiar área de poblamiento a lo largo de la costa, en especial por parte de los camanchacas ${ }^{3}$.

La etnohistoriadora peruana María Rostworowski, en varios de sus trabajos, desde el prisma de la etnohistoria colonial, ha aportado materiales documentales en extremo valiosos para la franja costera del extremo sur de Perú, para dilucidar su posible pertenencia étnica y su idioma. Si bien Rostworowski hace una somera mención a la existencia del término ayllos de camanchacas, para la costa norte de Perú, en el sitio Huanchaco, junto a Trujillo (1981a), no se ha encontrado información alguna suya referente a la presencia de ayllos de esta etnia en el extremo sur peruano, y menos aún, en el norte chileno. Bente Bittmann (1977; 1984a; 1984b; 1986) ha sido tal vez la investigadora en Chile que más antecedentes etnohistóricos ha recogido y examinado sobre su presencia en la costa norte de Chile. Recientemente, Victoria Castro (2001) ha ofrecido una valiosa síntesis de los diferentes aportes de los investigadores, poniendo particular acento en su identidad cultural. Se ha revisado prolijamente los trabajos de todos estos autores, y ninguno hace referencia a la existencia de esta estructura

\footnotetext{
3 Se ha discutido in extenso su hipótesis (Larraín 1987), que a los autores parece un tanto peregrina.
} 
social comunitaria dual (el ayllu) entre pescadores camanchacas o changos. Por lo que parecería que este trabajo es el primero que enfoca este tema específico: la presunta presencia de ayllus de camanchacas en la costa norte chilena.

\section{La presencia temprana de un ayllu de camanchacas en Iquique colonial}

Lo novedoso del documento inédito que aquí se examina e incluye como elemento probativo, es que no solo se menciona aquí a los camanchacas, o camanchas (como también se les llama, seguramente por error), como una agrupación étnica reconocible y diferente, sino que, además, se les asigna su pertenencia a un ayllu propio y particular. Se piensa que este punto es digno de la especial reflexión en el presente trabajo. Entre los muchos aspectos específicos de la cultura inca que ha estudiado el etnohistoriador norteamericano John Murra ${ }^{4}$, se encuentra la constitución, persistencia y rol del ayllu en la cultura colonial. La siguiente es la definición que él entrega, en uno de sus artículos tempranos, sobre este elemento estructurador de la sociedad inca:

"One of the most controversial and poorest documented of Andean institutions is the ayllu, the kinship unit in the local social organization. The chief deficiency in our study is the absence of materials on the functioning of the ayllu in particular circumstances. In the Huarochiri material, the ayllu is taken for granted; it is, alas, insufficiently described, but it does appear in a wide variety of cultural contexts: ceremonial, economic, historical" (Murra, 1961: 55).

Existe una multitud de trabajos dedicados al estudio de distintos aspectos del ayllo, tanto en el mundo cultural quechua como en el aymara (Rowe, 1946; Tschopik, 1946; Valcárcel, 1943; Métraux, 1959; Earls, 1971;

\footnotetext{
4 En quien se reconoce al infatigable propugnador de los estudios etnohistóricos en Perú y Chile.
}

Espinoza Soriano, 1981; Harris, 1978; Pease, 1981; Rostworowski, 1981b; Platt, 1981; Godoy, 1985; Gundermann, 2003), dado que este era, a nivel local, el último y necesario eslabón de la estructura social inca y aymara. Huellas y rastros de la presencia de ayllus entre los grupos pobladores de las quebradas y altiplano en el norte chileno se tiene por doquier, donde se encuentra también la denominación complementaria de arajj saya o maqha saya. Y no solo durante la época colonial, sino también hasta el día de hoy.

El ayllu fue una institución andina típica, que ciertamente antecede al Imperio Inca. Este la asume, la reestructura y la adapta a sus necesidades tributarias y a las vicisitudes de expansión geográfica del Incanato. No es el momento de profundizar aquí en sus múltiples acepciones o significados: de orden ocupacional, étnico, exogámico, familiar o de tipo de descendencia. Equiparado por algunos a la comunidad o a la parcialidad hispana, ha sido considerado como una entidad misteriosa, casi imposible de identificar, enigmática y aun inútil. El tema ya lo ha caracterizado y sintetizado bien Godoy (1985), en su detallado análisis del rol fiscal del ayllu andino.

La pregunta que se hace aquí, a propósito del hallazgo del curioso texto que se presenta más abajo, es cuál podría ser el sentido exacto de la nominación de un aillo de camanchacas. ¿Se tratará aquí solamente de una derivación y traspaso de una nomenclatura altiplánica o de las quebradas agrícolas, a organizaciones y comunidades indígenas de la costa?; ¿será que el cura visitante tan solo identificó con este apelativo y con este nombre a una población camanchaca de cierta consideración?; ¿qué rol jugaba este aíllo en el sistema socioeconómico de explotación del guano en la isla de lque-ique?; ¿conservó la iglesia y el cura, al bautizar a niños pertenecientes a esta etnia, una denominación que ellos se daban a sí mismos? En otras palabras, ¿es una autoidentificación que usan los camanchacas costeños, o se trata de una denominación extrínseca y foránea, que les impone, por similitud con la estructura social del interior, el cura visitante de Tarapacá? Se tratará de dar una opinión al respecto. 


\section{Sobre la existencia de ayllus en la costa sur peruana}

Por cierto, sin pretender decir la última palabra aquí propone más adelante una hipótesis que a propio juicio podría explicar el uso de este término, primariamente en uso entre los quechuas o aymaras del interior, es decir, entre grupos agroganaderos. Se parte de la base de que la etnohistoriadora María Rostoworowski nunca -que se sepa- ha hecho referencia en sus escritos a la presencia de ayllos de camanchacas. En sus trabajos, basados en el examen de una copiosa documentación histórica de archivos, jamás indica la existencia de esta entidad socioeconómica entre las agrupaciones étnicas de los pescadores de la costa sur de Perú. Sin embargo, reseña la existencia de aillos en Huanchaco (Trujillo) y en la costa de Lambayeque (1981); pero no se trata aquí obviamente de camanchacas sino de pescadores de la costa de Moche (¿Mochica?). En resumen, ningún autor peruano, chileno o extranjero, se ha referido a la existencia de aillos de camanchacas en la costa. De aquí la novedad que ofrece el análisis del presente texto.

\section{Los archivos parroquiales, rico venero de estudios demográficos}

Se piensa que el tema no está de ninguna manera agotado, porque a medida que los historiadores y archiveros van descubriendo y analizando textos hasta ahora inéditos, nuevas facetas del tema van apareciendo, creando nuevas interrogantes o aclarando dudas anteriores. Parece obvio que los documentos coloniales procedentes de las Libros Parroquiales sean un rico venero de datos al respecto. La autoridad religiosa española, obispos y sacerdotes, se impusieron la tarea de cristianizar a los indios, no tanto por afán de ejercer un estricto control social y económico sobre ellos -como se ha sostenido como única motivación-, sino por muy poderosas razones de orden religioso. En efecto, por tal motivo dondequiera que había agrupaciones humanas de alguna importancia, se levantaban rápidamente capillas o iglesias, para su evangelización. Es precisamente este caso.
El axioma eclesiástico vigente ya desde la Edad Media, extra ecclesiam nulla est salvatio (fuera de la Iglesia [católica] no hay salvación), imponía a la mente cristiana y sobre todo a los predicadores y evangelizadores la necesidad de pregonar el Evangelio, de bautizar y administrar los sacramentos a los indígenas, como único medio de asegurar su pertenencia a la Iglesia y, por su intermedio, su salvación. El bautismo era la única puerta de entrada a este "Reino de Dios" prometido por Cristo. De este modo, se ponía en práctica lo dicho por Jesús en el Evangelio, al despedirse de sus discípulos en un monte de Galilea:

"Id por todo el mundo y haced discípulos, bautizándolos en el nombre del Padre, del Hijo y del Espíritu Santo, enseñándoles a observar todo lo que yo os he mandado" (Mateo 28, 12).

El Tercer Concilio Limense (1584), instrumento básico para la pastoral católica durante la Colonia temprana, y que rige por entonces en todo el Virreinato peruano, es explícito al respecto:

"....y aunque en todas partes tienen los perlados como pastores que son de esta grey de Christo, obligación de accudir a lo principal de su oficio, que es declarar la Ley de Dios: pero muy más especialmente corre esta obligación en estas partes donde ha sido Dios Nuestro Señor servido de plantar en su iglesia estas nuevas plantas de los Indios. Los cuales, así por ser del todo nuevos en nuestra fé, como por traer el entendimiento mas corto y menos exercitado en cosas espirituales, tienen summa necesidad de ser quanto sea posible ayudados con el buen modo y traza de los que les enseñan: de suerte que la diligencia y destreza de los maestros, supla la rudeza y cortedad de los discípulos para que lleguen a formar el debido concepto de cosas tan soberanas, como nuestra fé les ofrece..." (Tercer Concilio Limense, 1584: folios 7 y $8^{5}$ ).

\footnotetext{
5 Destacado personal.
} 
Ahora bien, teniendo en cuenta esta obligación moral de obispos y sacerdotes, inherente al legado espiritual de Cristo, se entiende muy bien por qué se procuraba, por todos los medios, evangelizar, llevar misiones, levantar capillas y sostener en ellas a sacerdotes para introducir en el Reino; esto es bautizar y cristianizar a los indígenas idólatras y paganos. Cualquier culto a cualquier deidad, era interpretada como idolatría, y era por tanto execrable, condenable. Y merecía ser extirpada. Por eso surgirán los extirpadores de idolatrías, en las comunidades que seguían fieles a sus viejas creencias del tiempo del Incario. Era el efecto de una época de intransigencia religiosa que solo permitía el ejercicio de una sola fe y de una sola creencia.

Siendo esto así, en una elemental lógica cristiana se entiende perfectamente bien lo siguiente:

a) Por qué todos debían ser bautizados, a poco de nacer. Morir sin el bautismo, equivalía por entonces a una condenación cierta. La salvación solo se lograba mediante el bautismo, que es la imprescindible puerta de entrada a la Iglesia.

b) Por qué el sacerdote oficiante debe nombrar padrinos y madrinas de los recién bautizados, para que estos instruyan a sus ahijados en las verdades de la fe, y les den ejemplo de vida cristiana; por tal motivo, los padrinos y madrinas deben ser cristianos de vida ejemplar ${ }^{6}$.

c) Por qué los sacerdotes acudían a dar el servicio religioso a todas las agrupaciones humanas y levantaban en todas ellas templos o capillas, aun en las más pequeñas. En la costa de Tarapacá: Pisagua, Iquique y Loa no serán por cierto una excepción. Y por ello existen capillas católicas en todos aquellos lugares que es-

6 La Iglesia Católica sigue hoy reconociendo la importancia de los padrinos y madrinas del bautismo. En el Catecismo actual de la Iglesia (versión 1992) se anota en el párrafo № 1255: "para que la gracia bautismal pueda desarrollarse es importante la ayuda de los padres. Ese es también el papel del padrino o de la madrina, que deben ser creyentes sólidos, capaces, y prestos a ayudar al nuevo bautizado, niño o adulto, en su camino de la vida cristiana. Su tarea es una verdadera función eclesial" (Iglesia Católica, 1992: 291-292). taban poblados desde antiguo por grupos indígenas.

d) Por qué se administraba el sacramento de la extremaunción o unción de los enfermos a los que se acercaban a la muerte.

e) Por qué se les enterraba en tierra sagrada, esto es en cementerios especiales bendecidos al efecto. $Y$ durante siglos, dentro de los muros de las mismas iglesias o en sitios contiguos a estas.

Lo señalado anteriormente apunta a la importancia antropológica y demográfica de los Libros de registros de Bautismos, Matrimonios y Defunciones. Porque los sacerdotes y párrocos debían dar cuenta del cumplimiento de su deber como predicadores de la salvación y dejar testimonio escrito de ello. Esta obligación moral, nacida de un explícito mandato evangélico, hace suponer que de necesidad, todos los nacidos vivos eran siempre bautizados y todos debían ser, además, indoctrinados en la fe cristiana.

Por lo tanto, dondequiera que se tenga un registro escrito de bautismos, matrimonios y defunciones, sostenido por un largo período de tiempo, se tiene prácticamente, el dato preciso de la evolución demográfica de la comunidad entera. Por lo que resulta posible, donde hay Libros que se extienden por un largo período, reconstruir en gran medida la dimensión y tamaño de la comunidad respectiva, calcular su número y grado de parentesco, obtener la media de vida y otras informaciones valiosas atingentes a la evolución de la población, como la presencia de epidemias o terremotos, que hubieren afectado la vida de la comunidad. Hasta es posible, en alguna medida, hacer pirámides de población por períodos.

\section{Organización territorial y estructura social de un pueblo de pescadores}

Cómo se constituyeron y organizaron las poblaciones de pescadores en pueblos costeros, es un tema que ha sido examinado $y$ debatido pero no del todo esclarecido hasta hoy. María Rostworowski habla de que los pescadores a lo largo del sur de Perú y del actual norte de Chile formaron parcialidades con sus principales o señores con un orden 
jerárquico, y que reconocían una territorialidad de sus playas y lugares específicos de extracción y trabajo en el litoral (Rostworowski, 1975; Rostworowski, 1981a). Explícitamente:

"Numerosas son las referencias a pescadores establecidos en el litoral en tiempos prehispánicos. En el ámbito andino, las playas eran propiedad de los grupos instalados en sus cercanías. No solo eran privadas las riberas, sino lo fueron los determinados lugares donde se efectuaban diversas suertes de pesca. En 1566 el Visitador Gregorio González de Cuenca durante su estadía en el norte, ordenó que el mar fuese común para todos, afirmación que causó trastorno y malestar entre la población indígena. En vista de la confusión provocada y de las protestas de los señores pescadores, Cuenca decidió conservar la antigua costumbre, hasta no proveer otra cosa" (Rostworowski, 1981a: 84).

Esta cita permitiría concluir que existió, también en la costa de la mar, un concepto claro de territorialidad, entendido como el derecho o costumbre que estas comunidades habrían ejercido en el espacio en que habitaban, y que el español en un momento quiso - probablemente en forma inconscientedesestructurar, al declarar que el mar y sus caletas pasaban a ser, de ahora en adelante, comunes a todos.

Se sospecha que, en los documentos analizados para la costa de Iquique, el concepto de ayllu no ha sido empleado por el hecho que sus miembros se autodenominasen así. Pero obviamente tampoco se debe atribuir al azar. Lo más probable, a propio juicio, es que el hecho de poseer a los ojos de los españoles (autoridades o sacerdotes visitantes), caudillos, jefes locales o señores, de mostrar una cierta organización social y una patente pretensión de control y dominio sobre un determinado territorio costero, mediante el frecuente usufructo sobre determinadas playas, islas o roqueríos y sus recursos propios, los hizo ser acreedores a este nombre. A españoles acostumbrados a tropezar por todas partes con esta institución en las zonas agrícolas o pastoriles del interior, donde la endogamia y la solidaridad grupal era evidente en todas sus actividades tanto económicas como festivas, el encuentro con comunidades o parcialidades de pescadores, asentadas en caletas de la costa, el empleo de tal denominación les pareció, sin duda, la más precisa y acertada. Los sacerdotes, religiosos y visitadores vieron en pleno funcionamiento una organización económica (de extracción del guano y secado de mariscos y pescados para un activo comercio con el interior) en un claro contexto territorial (aldeas) y la presencia de un número de familias de indígenas nada despreciable, formando así unidades reconocibles, distinguibles claramente por su modo de vida de otros grupos de lengua y cultura diferente, y por añadidura, ligados profundamente al recurso marino (pesca, marisqueo, extracción del guano, caza marina) y sus actividades conexas.

Queda, sin embargo, una duda: ¿por qué un solo sacerdote, en este caso Joseph Cavesas, usa esta denominación en varias Partidas de Bautismo?; ipor qué no lo hacen otros sacerdotes antes o después de ese corto período de tiempo? Realmente, no se sabe, y probablemente nunca se sabrá a ciencia cierta. ¿Qué tiene de diferente este sacerdote evangelizador respecto de otros que ejercen funciones sacramentales en la misma zona?

Para John Murra, el concepto de ayllu en los Andes fue difuso porque la organización del espacio y de la economía indígena presentó variantes zonales significativas, entendiéndose así que modelos propuestos para las comunidades altoandinas podían no haber sido idénticos en todas las sociedades indígenas a lo largo de los Andes (Murra, 1961).

En el caso de los pescadores ha quedado así de manifiesto, pues se sabe que más al norte de la zona de estudio, como en los valles de Arica, los pescadores camanchacas mantuvieron tierras de cultivos, valle adentro cerca de Ocurica (Hidalgo, 2004).

El caso de los camanchacas de Iquique parece haber sido igualmente distinto al de otras agrupaciones étnicas, por presentarse aquí un panorama ecológico diferente, muy distinto al del interior sujeto a regadío, y propio de una zona esencialmente arreica, en la franja costera entre la localidad de Pisagua y la desembocadura del río Loa. Aquí no había tierras cultivables cercanas. 
El recurso hídrico era extraordinariamente escaso y hasta el aprovisionamiento de agua potable era solo eventual y problemático y había que traerlo en balsas desde las antiguas vertientes o aguadas de la costa, lo que requería de un grado de sociabilidad y cooperación mutua importante, desde tiempos prehispánicos.

\section{¿Qué pudo significar la existencia de un ayllu de camanchacas en Iquique?}

Así, al analizar, en las páginas que siguen, Partidas de Bautismo que hablan de camanchacas, o, más específicamente, de la presencia de ayllos de camanchacas, y aun de mitades o "moieties" [arajj saya], se lee entre líneas varias cosas significativas desde el ángulo de su estructura social:

a) Que existían grupos humanos que se denominaban o eran denominados camanchacas por ser claramente diferentes del resto de la población.

b) Que estos grupos eran distinguidos conscientemente de los españoles, de los negros, mulatos y zambos.

c) Que debieron tener cierta importancia demográfica como para constituir ayllus, es decir, agrupaciones sociales organizadas (clanes), con derecho a usar un cierto territorio y recursos ecológicos costeros.

d) Que la mención explícita en algunos casos, al margen de la partida bautismal, de una mitad o moiety nombrada arajj saya, estaría apuntando a la presencia de la estructura dual tan propia y característica del ayllu andino. La referencia explícita a ayllus de camanchacas, y a moieties (arajj saya), estaría sugiriendo, o tal vez probando, que por entonces constituían grupos sociales perfectamente identificados por los sacerdotes encargados de su evangelización. Si bien es cierto que solo se tiene en este Archivo tres menciones de individuos pertenecientes a un ayllo de camanchacas, es este ya un dato importante por venir de un mismo breve período de tiempo.

e) Que probablemente por esas mismas fechas ya existía en el puerto de Iquique (o Yqueyque, con su grafía antigua) alguna iglesia o capilla para atender a la feligresía indígena, seguramente la más importante de la primitiva población del puerto $^{7}$.

Se han revisado cuidadosamente muchas partidas de bautismo, entre los años 1652 y los años 1730 y si bien hasta solo se han encontrado cuatro partidas siguiendo las pistas de investigaciones anteriores sobre el tema (Odone, 1990), estas representan, por esas tempranas fechas del puerto de Iquique, la prueba de la existencia de una comunidad organizada de camanchacas, suficiente como para ser denominada por el sacerdote a cargo como un ayllo, a semejanza de los ayllos existentes en los pueblos de origen aymara (o quechua) del interior. La denominación ayllo, evidentemente, no habría sido usada

\footnotetext{
7 Hacia las mismas fechas de estas partidas de bautismo, apenas unos pocos años antes, en julio de 1680 , se nos presenta un dato significativo proveniente de la relación del corsario John Esquemeling (1893), que fuera parte de la expedición del corsario Sharp, quien atacara la isla del guano frente a Iquique, apoderándose de algunos españoles para interrogarlos. El siguiente es su relato:

"En dirección al punto de donde venía el viento, hay una pequeña isla de veinte o treinta casas, la que posee una pequeña capilla [chapel] próxima, construida de piedra, y como adorno, sobre ésta, se encuentra totalmente cubierta de cueros de pieles de focas [seals]. Encontraron unas cincuenta personas en este villorrio [hamlet], pero en su mayor parte huyeron al arribo de nuestro bote. A esta isla, frecuentemente llegan barcos desde Arica, cuya ciudad no está muy distante, y vienen en busca de arcilla [clay] y ya se han llevado la mayor parte de este elemento. Los pobres indígenas, habitantes o nativos de esta isla, son obligados a traer toda el agua fresca que ellos usan, desde una distancia total de once leguas, es decir, desde un río nombrado Camarones, que se encuentra a sotavento de la isla. La embarcación en la cual ellos acostumbran traerla, había partido en busca de agua cuando nuestros hombres desembarcaron en el lugar" (1680: 261-262; traducción y subrayado nuestro).

Este relato muy circunstanciado y preciso, nos muestra en la isla del guano (iy no en el continente!) a una población relativamente importante (20-30 chozas de indios) y explícitamente reseña la presencia de una capilla propia [chapel], construida al estilo indígena, y forrada con pieles de lobos marinos. Ese número de casas nos sugiere una población aproximada a las 100 personas, a lo menos. Fue aquí, en esta misma capilla, posiblemente, donde el sacerdote Joseph Cavesas ofició los bautismos de varios niños pequeños, hijos de camanchacas. Este relato es para nosotros muy valioso pues corrobora la existencia de un ayllo en un villorrio de gran número de residentes pescadores.
} 
para aislar e identificar a un número muy escaso de personas, sin algún grado notorio de organización. Que los indígenas que trabajaban en el puerto de Iquique, sobre todo en la explotación, carguío y transporte del guano de la isla, no eran muy pocos, y estaban organizados en sus faenas, lo testimoniará aun, mucho más tarde, Antonio O'Brien, en su Descripción del Puerto de Iquique.

En efecto, casi un siglo más tarde, en 1765, O'Brien señala expresamente su presencia en su Descripción del Puerto de Iquique (Iquiqui). Textualmente señala:

"El Pueblo de Yquiqui es muy corto, y sus moradores, que todos son Naturales, se ocupan en sacar el Guano de la Isla, para el cultivo de las tierras de las Provincias, de Arica, Moquegua, y Arequipa aunque esta Pesca les suele costar a muchos la vida a causa de que las mas de sus Embarcaciones son balsas echas de Cuero de Lobo Marino Ilenas de Ayre, las que vistas por los Taburones (sic por tiburones) que hay ya cevados, las muerden hasta romperlas, y como en faltandoles el Ayre se bàn los Pellejos afondo, se comen al Pescador (O'Brien, 1765).

Para O'Brien, en esta cita, el vecindario de Iquique, aunque corto, se compone solamente de "naturales", esto es, de indígenas dedicados a la extracción del guano de aves marinas.

Por fin, aunque escuetas y breves, las Partidas de Bautismo que se exhiben a continuación, anotadas en su margen como camanchas, o aillo camanchaca, apuntan claramente a la persistencia hasta bien entrado el siglo XVII de un grupo indígena costero, bien identificado por sus características étnicas, sociales, culturales y económicas. El cuidado que manifiesta el cura de Tarapacá, encargado de estampar las partidas, don Joseph Cavesas, por señalar en las márgenes del Libro el lugar preciso del bautismo (Puerto) y la referencia social (aillo), reveladora de su identidad étnica, es prueba de su preocupación por develar la pertenencia étnica, que por esos años era de vital importancia para lograr, a través del tiempo, un seguimiento de la evolución demográfica de la comunidad.

\section{Apellidos indígenas en Iquique a fines del siglo XVII (1686- 1697)}

\section{Otros antecedentes de la zona}

El Cuadro $N^{\circ} 1$ muestra todos los apellidos de origen indígena que se han detectado en Partidas de Bautismo del Libro de la Parroquia de Tarapacá que lleva el título Libro de Bautismos y Defunciones de San Lorenzo de Tarapacá, 1685 a 1706. En el libro inmediatamente anterior, el más antiguo que se conozca de esta Parroquia, y cuyo título es $\mathrm{Li}$ bro Bautismos, Matrimonios y Confirmaciones de San Lorenzo de Tarapacá (1652-1699), no hay mención alguna a la presencia de camanchacas o a algún aillo de camanchacas, aun cuando se consigna bautismos y matrimonios verificados en Pisagua.

En cambio, en el Libro de Bautismos de Santo Tomás de Camiña, de 1653 a 1695 (foja $140 \mathrm{v}$ ), aparece una niña camanchaca bautizada allí en fecha 15 de abril de 1660, y nombrada como "Juana (?) la hija de Diego Ala y de Maria Micane (... roto) fue su padrino... Diego Quilacoia". La denominación camanchaca aparece claramente al margen izquierdo de la Partida correspondiente. Hasta ahora, no se ha encontrado ninguna otra mención de camanchacas en los Libros de Camiña, por esas mismas fechas. Esta referencia, al igual que la mención de camanchacas en Iquique, fue pesquisada por nosotros a través de una cita en el texto de la tesis de Carolina Odone (1994), trabajo que indujo a realizar una investigación más prolija.

Del análisis específico del Cuadro $N^{\circ} 1$, se extrae lo siguiente:

a) Lo primero que salta a la vista aquí es la clara diferencia entre apellidos evidentemente aymaras (o quechuas), como Mamani, Quispe, Guaitari, Cayo, Paucay, y todos los restantes, que parecerían ser propios de camanchacas de la costa. Los segundos, son mucho más abundantes que los primeros;

b) Los apellidos aymaras (o quechuas) corresponden aquí a personas que actúan en la ceremonia bautismal en calidad de padrinos o madrinas de los niños bautizados 


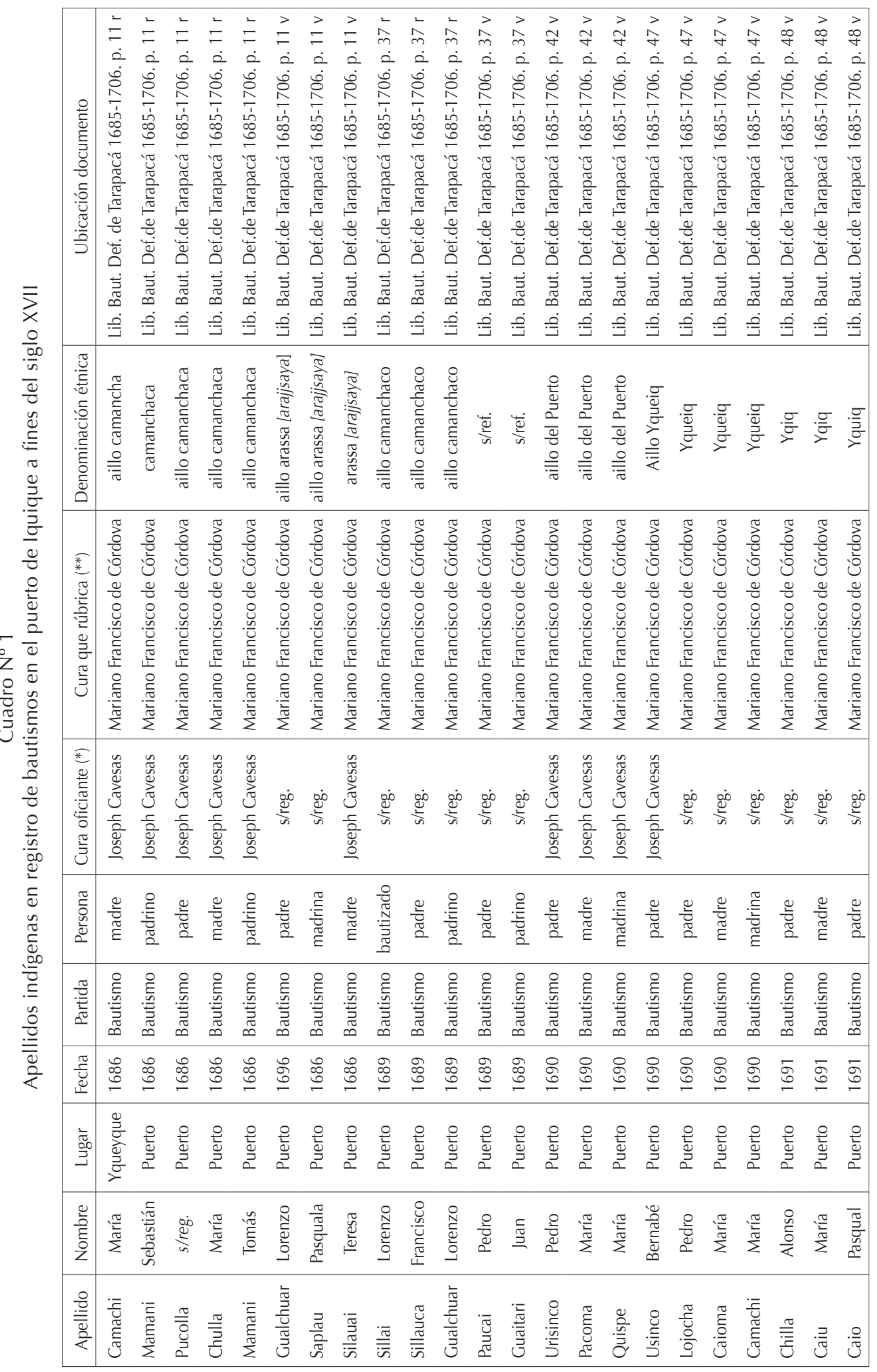




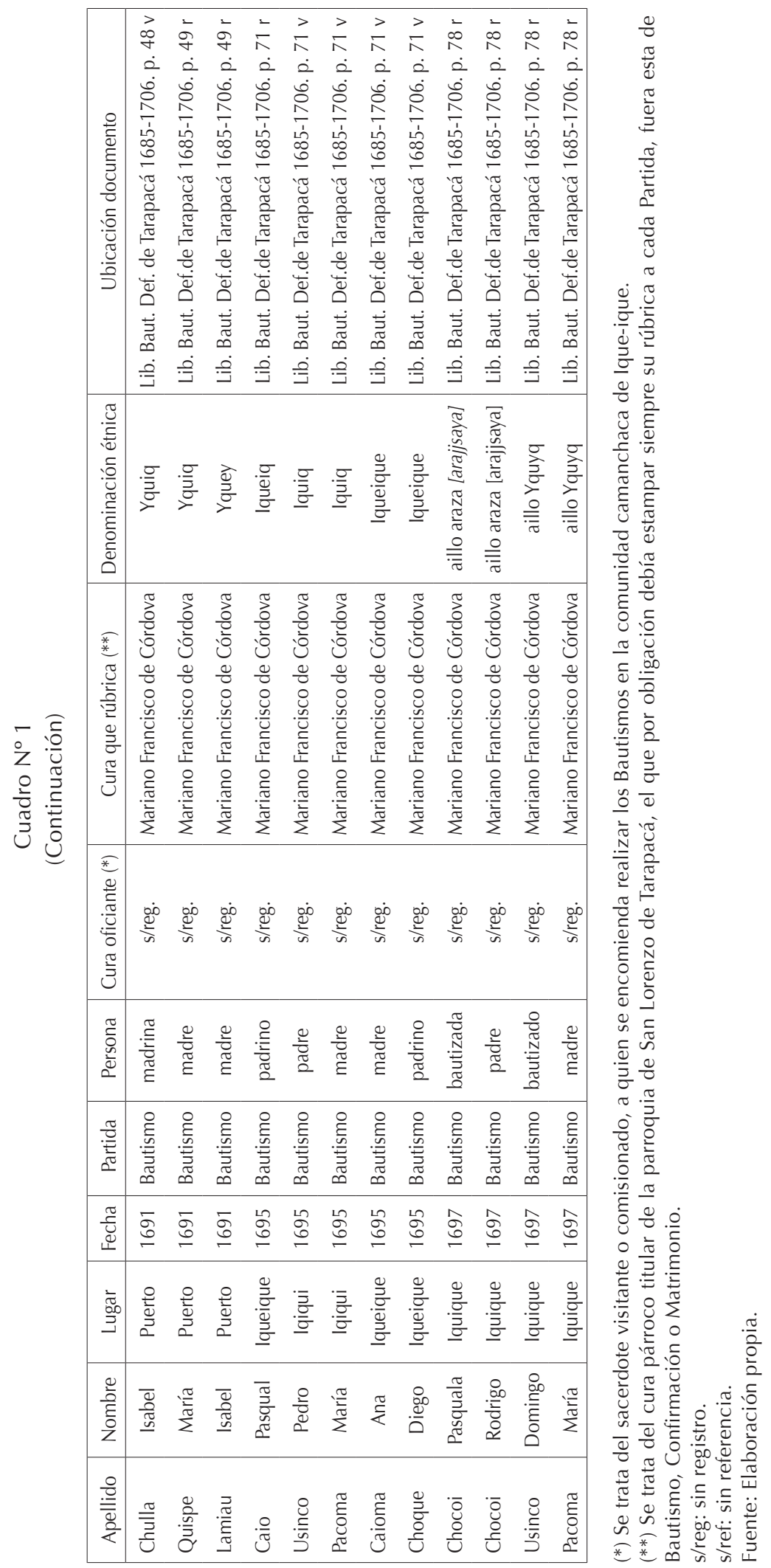


costeños. A lo que parece, estas personas serían habitantes del interior, perteneciendo a las comunidades de las quebradas (Tarapacá, Mocha, Sibaya y otros pueblos vecinos). Pero, además, es interesante reseñar que solo se elige, por parte del sacerdote, a padrinos o madrinas entre estos indígenas aymaras (o quechuas), ya suficientemente aculturados y adoctrinados en la fe cristiana. La razón es obvia: el sacerdote debía confiar a los recién iniciados en la fe -de acuerdo a lo señalado por los Concilios Limenses-, a personas conocedoras de los misterios de la nueva religión, de modo que pudiesen cumplir a cabalidad los requisitos de guiar y enseñar a los nuevos "hijos de Dios" en las "verdades de la fe".

c) Todas las menciones a camanchacas o aiIlo de camanchacas, han sido hechas por el sacerdote Joseph Cavesas en el lugar designado Ique-ique o, posteriormente, solo como Puerto. Siendo Ique-ique el puerto más próximo y natural de Tarapacá, desde tiempos muy tempranos, es evidente que no podría tratarse aquí de otro puerto. Se sabe, además, que Ique-ique era parte integrante de la jurisdicción de la parroquia de San Lorenzo de Tarapacá (Advis, 1990). El puerto de Pisagua dependía de la parroquia de Camiña y el puerto de Loa, de la parroquia de Pica. Por tanto, no podría haber la menor duda al respecto.

d) Todas las partidas quedan refrendadas y rubricadas por el párroco de San Lorenzo de Tarapacá, don Mariano Francisco de Córdova. Cualquier posible error habría sido subsanado por este.

e) Los apellidos que se consideran tentativamente como camanchacas (todos los otros indicados en el Cuadro $\mathrm{N}^{0} 1$ ) siguen subsistiendo, según propias pesquisas, hasta bien entrado el siglo XVIII, aunque ya no se nombre nunca más un aillo de camanchacas. Sobre todo en el elemento femenino, que muestra un mayor apego a las tradiciones familiares, lo que estaría indicando que los camanchacas subsisten y perduran aún un buen tiempo, pero probablemente fuertemente mestizados con elementos étnicos del interior, con los que se van relacionando en términos de parentesco ritual (compadrazgo), o por razones comerciales (trueque). Se debe reflexionar en este contexto, que la gran proximidad al puerto de Ique-ique del mineral de Huantajaya, explotado en sus vetas de plata desde el siglo XVI, sin duda alguna atrajo a una población flotante del interior como trabajadores y obreros. Y estos, no puede dudarse, bajarían frecuentemente a la costa a abastecerse, o escapaban por períodos de las duras faenas mineras. Hubo pues aquí en Huantajaya un contingente humano muy potente, situado a escasos $10 \mathrm{~km}$ o $12 \mathrm{~km}$ del puerto de Ique-ique y de la costa del Pacífico.

f) Queda por averiguarse por qué tan solo el sacerdote Joseph Cavesas designa al aillo de camanchacas en Ique-ique. Otros sacerdotes posteriores, ya no lo nombrarán. ¿Por qué?, ¿será, tal vez, por que dejó de llamarse así, o será porque la mayoría de sus componentes, paulatinamente, fueron aymarizándose (o quechuizándose), mediante la llegada de elementos exogámicos, máxime varones, desde el interior andino? Un seguimiento más acucioso a la acción pastoral y sacerdotal de este sacerdote podría, tal vez, ayudar a develar este enigma.

g) Por fin, a manera de hipótesis, se sospecha que el sacerdote Joseph Cavesas, acostumbrado probablemente a adoctrinar y visitar las comunidades altoandinas, en las cuales el aillo era distintivo social particular, debió inconscientemente rotular de aillo a la comunidad de pescadores del puerto de Ique-ique, por su visible cohesión grupal, su actividad económica compartida y por su estrecha vinculación a las actividades de extracción del guano y pesca. Si fueron Ilamados, a veces, parcialidad, con el mismo argumento pudieron ser rotulados de ayllo, por los españoles, sin que necesariamente llegasen estos ayIlos costeros a ostentar la estructura dual típica del ayllo tradicional andino y/o a poseer su elaborada estructura societaria. En tal caso, esta aplicación del término no habría sido otra cosa, sino una simple réplica o un sinónimo del término comunidad o parcialidad. 
Transcripción del Documento base de este estudio

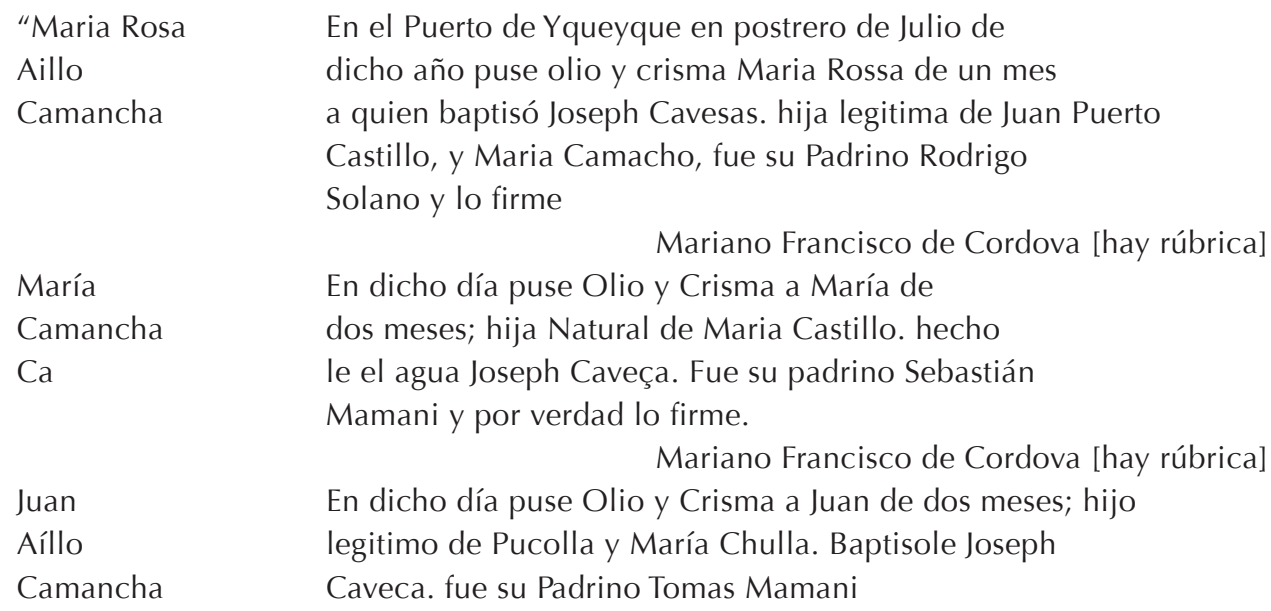

ca

Mariano Francisco de Cordova [hay rúbrica]

Fuente: Archivo Obispado de Iquique, 1686: 11.

Lorenso

En diecisiete dia del mes de junio de ochenta

Puerto

y nuebe [1689] puse olio i Crisma a Lorenso Sillai casi

Aillo de tres días, hijo legitimo de Francisco Sillauca i Maria Espi

Caman nossa, fue su padrino de todo Lorenso Gualchuar. i por

Chaco verdad lo firme.

Mariano Francisco de Cordova [hay rúbrica]

Fuente: Archivo Obispado de Iquique, 1686: 37.

\section{Consideraciones finales}

Aunque solo se tenga a mano, por ahora, cuatro anotaciones de bautismos de indígenas pertenecientes a un aillo camanchaca del puerto de Iquique, a fines del siglo XVI, este solo hecho ya se considera significativo y parecería estar probando la existencia de una cierta organización social del grupo de indígenas camanchacas encargados, desde tempranos tiempos, de la pesca, del secado de pescado y de la extracción del guano de la isla.

Por otro lado, estos camanchacas son identificados, al costado derecho del documento, y mediante un evidente subrayado, expresamente como del Puerto de Iquique. Nunca se les cita en otros puertos o caletas de la costa norte chilena.
Además, los apellidos indígenas reseñados en las partidas bautismales para los correspondientes padres de las criaturas que se bautizan, por ejemplo Camacho (seguramente Camachi), Pucolla, Chulla, Sillay, Sillauca, Gualchuar y otros más, no parecen quechuas ni aymaras; y ciertamente, menos aún atacameños. La presencia de estos apeIlidos abogaría claramente por la existencia de un grupo étnico muy diferente del aymara y del quechua. ¿Se tratará, tal vez, aquí de apellidos de origen puquina, o de alguna otra lengua desconocida de la costa?

Por otra parte, el análisis detallado de los apellidos indígenas encontrados en el Libro de Bautismos del período 1680-1700, indica que la referencia a un aillo camanchaca, anotada al margen de la partida, correspon- 
de, muy exactamente, a la anotación hecha durante el período de visita al puerto de Iqueique por el sacerdote Joseph Cavesas. Tan pronto este falta, se observa que desaparece, a la vez, la mención al aillo camanchaca. ¿Cómo interpretar este hecho? Después, en las anotaciones de las partidas siguientes, solo se anotará el término aillo, pero sin la referencia étnica correspondiente (camanchaca). A todas luces, el aillo sobreviviente es el de los camanchacas, pero su denominación étnica se omite de aquí en adelante. ¿Por qué? No se sabe.

Otro aspecto de gran interés es el hecho repetido de que los padrinos o madrinas señalados en los bautismos, sean invariablemente indígenas del interior: aymaras (o quechuas $)^{8}$. Nunca lugareños. Apellidos como Mamani, Quispe, Cayo (Caio) aparecerán ahora en escena. Las razones de este hecho ya se han dado más arriba.

Solo para el puerto de Iquique se ha encontrado referencia a la existencia de un ayllo indígena. Se han encontrado algunas escasas partidas de bautismo de camanchacas reseñadas para Pisagua (anotadas en el curato de Camiña), pero no se menciona en ellas para nada la existencia de un aillo.

Se tiene, pues, la certeza de que para fines del siglo XVII existía todavía en la isla de Iquique y su contorno una agrupación de indios Ilamados camanchacas, los que por su

8 El hecho de poner la etnia quechua entre paréntesis, junto a la aymara, se debe al convencimiento de que algunas de las comunidades serranas de Tarapacá pudieron tener ancestros quechuas. La aymarización de los pueblos serranos de Tarapacá no parece ser de data muy antigua $y$, al parecer, existieron pueblos formados por mitmas incásicos, a la vera del Qhapaq Ñan o Camino del Inca. Hasta hoy, hay comunidades que insisten en su ancestro quechua (como es el caso especialmente de Mamiña y Miñe-Miñe y aun Tarapacá) y que se niegan a integrarse a la CONADI (Corporación Nacional de Desarrollo Indígena) en calidad de aymaras. Todavía mayor confusión aporta el hecho de que, en ambas etnias, los apellidos son prácticamente los mismos, a diferencia de lo que ocurre con otras (como atacameños y diaguitas). La presencia de comunidades de ancestro quechua en las regiones de Arica y Tarapacá, a la vera del antiguo Camino del Inca, es un tema de gran interés, abierto hoy a la discusión. número y seguramente por su grado de organización en el trabajo comunitario, merecieron el empleo del término aillo dado por el sacerdote Joseph Cavesas y luego rubricado por el párroco titular de Tarapacá, don Mariano Francisco de Córdova.

Para el período inmediatamente siguiente a la desaparición de la mención al aillo camanchaca, en el margen de las partidas de bautismo, se puede observar la repetición de casi los mismos apellidos: Gualchuar, Camachi, Usinco, Lojocha, Caioma, Chulla, Chocoi; es decir, los mismos grupos étnicos y sus apellidos continúan presentándose, máxime entre las mujeres, pero se omitirá en adelante la designación de camanchacas, por razones que por ahora no se entienden. ¿Será, tal vez, que el mestizaje se está ahora imponiendo, con la aparición de mulatos, mestizos y zambos, desapareciendo poco a poco los antiguos camanchacas? Es posible.

Finalmente, se hace imperioso seguir investigando, en esta misma línea de estudio, los antecedentes que arrojan las partidas tempranas de Bautismo, Confirmaciones, Matrimonios y Defunciones que correspondan a indígenas pobladores de la costa, que permitan identificar la presencia de ayllos o agrupaciones indígenas $y$, probablemente, intentar trazar grupos de parentesco entre ellos, tal como Bittmann (1984b) lo hizo para Cobija.

\section{Agradecimientos}

Especial gratitud al obispo de la diócesis de Iquique, monseñor Marco Antonio Órdenes Fernández, por haber facilitado el acceso a la consulta y examen de documentos del Archivo episcopal de Iquique. Igualmente, a la señora Marcia Valenzuela, periodista del Obispado, por el apoyo prestado en este trabajo durante los meses dedicados al registro de información in situ. A Marta Peña Guzmán, por las finas atenciones en su casa en el curso del presente trabajo.

\section{Referencias bibliográficas}

ADVIS, P. La Doctrina de Tarapacá en el siglo XVI (Perfil Administrativo Eclesiástico). Camanchaca, 1900, No 12/13, p. 76-90. 
ARCHIVO OBISPADO DE IQUIQUE. Libro de Bautismos y Defunciones, San Lorenzo de Tarapacá, 1685-1706. Iquique: Obispado de Iquique, 1686.

BITTMANN, B. Notas sobre poblaciones sobre la costa del Norte Grande chileno. En: CASASSAS, J. M. (ed.). Aproximación a la Etnohistoria del Norte de Chile. Antofagasta: Universidad del Norte, 1977, p. 1-71.

BITTMANN, B. El programa Cobija: investigaciones antropológicomultidisciplinarias en la costa centro sur andina: notas etnohistóricas. En: MASUDA, S. (ed.). Contribuciones a los Estudios de los Andes Centrales. Tokio: Universidad de Tokio, 1884a, p. 101-149.

BITTMANN, B. Interrelaciones étnicas establecidas a lo largo de la costa del Norte de Chile y sur del Perú en el contexto de la Colonia, Ios camanchacas. Estudios Atacameños, 1984b, № 7, p. 443-454.

BITTMANN, B. Recursos naturales renovables de la costa del norte de Chile: modos de obtención y uso. En: MASUDA, S. (ed.). Etnografía e historia del mundo andino. Continuidad y cambio. Tokio: Universidad de Tokio, 1986, p. 269-334.

CAMACHO, J. M. Urus, Changos y Atacamas. Boletín de la sociedad Geográfica de la Paz, 1943, vol. 54, p. 9-35.

CASASSAS, J. M. La Región atacameña en el sig/o XVII. Antofagasta: Universidad del Norte, Imprenta Universitaria, 1974.

CASTRO, V. Atacama en el tiempo, territorios, identidades, lenguas (Provincia El Loa, II Región). Anales de la Universidad de Chile, 2001, № 13. Disponible en Internet: http://www.revistas.uchile.cl/index.php/ ANUC/article/view/2527/2442

EARLS, J. The structure of modern Andean social categories. Julian Steward Anthropological Society, 1971, № 3, p. 69-106.

ESPINOZA SORIANO, W. El fundamento territorial del ayllu serrano, siglos $X V$ y XVI. En: CASTELLI, A.; DE PAREDES, K. y MOULD DE PEASE, M. (comps.). Etnohistoria y antropología andina: segunda jornada del museo nacional de historia. Lima: Museo Nacional de Historia, 1981, p. 93-130.

ESQUEMELING, J. The Buccaneers of América (Alexandre Olivier Esquemeling 1645-1707). London: Swan Sonnenschein \& Co., 1893.

GALDÓS, G. Uros, Camanchacas, Changos, Puquinas y Yungas pescadores en Sud-Perú y Norte de Chile. Diálogo Andino, 1982, No 1, p. 13-29.

GODOY, R. State, Ayllu, and Ethnicity in northern Potosí. Anthropos, 1985, № 80, p. 53-65.

GUNDERMANN, H. La formación del espacio andino en Arica y Tarapacá. Revista de Historia Indígena, 2003, № 7, p. 87-138.

HARRIS, O. El parentesco y la economía vertical en el ayllo Laymi (Norte de Potosí). Avances, 1978, № 1, p. 51-64.

HERRERA, J. Las Etnias pescadoras del Extremo Norte: Indicadores Culturales para los denominados Changos. Ethno, 1997, $N^{\circ}$ 1. Disponible en Internet: www.csociales. uchile.cl/publicaciones/biblioteca/docs/ ethno/ethno1.pdf

HIDALGO, J. Pescadores del litoral árido de valles y quebradas del norte de Chile y su relación con agricultores, Siglos XVI y XVII. En: HIDALGO, J. (ed.). Historia Andina en Chile. Santiago: Editorial Universitaria, 2004, p. 431-469.

IGLESIA CATÓlICA. Catecismo. Santiago: Iglesia Católica, 1992.

LARRAÍN, H. Identidad cultural e indicadores eco-culturales del grupo étnico chango. Revista de Geografía Norte Grande, 1978-79, No 6, p. 63-76.

LARRAÍN, H. Análisis demográfico de las comunidades de pescadores Changos en el Norte de Chile en el siglo XVI. Tesis Maestría en Arte. En: New York, Departamento de Antropología, Universidad del Estado de New York, 1984.

LARRAÍN, H. Etnogeogeografía. Santiago: Instituto Geográfico Militar de Chile, 
Colección de Geografía de Chile, Tomo XVI, 1987.

LATCHAM, R. E. Quiénes eran los Changos? Anales de la Universidad de Chile, 1910, No 126, p. 377- 349.

LIZÁRRAGA, R. Descripción breve de toda la tierra del Perú, Tucumán, Río de la Plata y Chile. Madrid: Biblioteca de Autores Españoles, Ediciones Atlas, vol. 216, 1968.

MÉTRAUX, A. The Social and Economic Structure of the Indian Communities of the Andean Region. International Labor Review, 1959, No 79, p. 225-243.

MURRA, J. Social Structure in Andean Ethnohistory. Anthropological Quarterly, 1961, No 34, p. 47-59.

O'BRIEN, A. Descripción del Puerto de Iquique y su población indígena. Sevilla: MS Archivo General de Indias, legajo Charcas $N^{\circ}$ 490, 1765.

ODONE, C. La territorialidad indígena y española en Tarapacá Colonial (siglos XVI$X V I I I)$ : una proposición, Tesis Licenciatura en Historia. En: Santiago, Instituto de Historia, Pontificia Universidad Católica de Chile, 1990.

PEASE, F. Ayllu y parcialidad, reflexiones sobre el caso de Collaguas 2. En: CASTELLI, A.; DE PAREDES, K. y MOULD DE PEASE, M. (comps.). Etnohistoria y antropología andina. Lima: Museo Nacional de Historia, 1981, p. 19-34.

PLATT, T. The role of the Andean ayllu in the reproduction of the petty commodity regime in northern Potosi (Bolivia). In: LEHMANN, D. (ed.). Ecology and Exchange in the Andes. Cambridge: University Press, 1981, p. 27-69.
ROSTWOROWSKI, M. Pescadores, artesanos y mercaderes costeños en el Perú prehispánico. Museo Nacional, 1974, № 41, p. 311-349.

ROSTWOROWSKI, M. Recursos naturales renovables y pesca, siglos XVI y XVII. Lima: Instituto de Estudios Peruanos, 1981a.

ROSTWOROWSKI, M. La vOZ "parcialidad" en su contexto en los siglos XVI y XVII. En: CASTELLI, A.; DE PAREDES, K. y MOULD DE PEASE, M. (comps.). Etnohistoria y antropología andina. Lima: Museo Nacional de Historia, 1981b, p. 35-45.

ROSTWOROWSKI, M. La Región del Colesuyu. Chungará, 1986, № 16-17, p. 127135.

ROWE, J. Inca Culture at the time of the Spanish Conquest. In: STEWARD, J. (ed.). Handbook of South American Indians, vol. 2. Washington: United States Government Printing Office, 1946, p. 183-330.

TERCER CONCILIO LIMENSE. Doctrina Christiana y Catecismo para instrucción de los Indios y de los demás personas que han de ser enseñados en nuestra Santa Fé. Lima: Impreso con licencia de la Real Audiencia de la Ciudad de los Reyes, por Antonio Ricardo, año de MDLXXXIIII, 1584.

TSCHOPICK, H. The Aymara. In: STEWARD, J. (ed.). Handbook of South American Indians, vol. 2. Washington: United States Government Printing Office, 1946, p. 501-573.

UHLE, M. Wesen und Ordnung der altperuanischen Culturen. Berlin: Biblioteca Ibero-Americana, Colloquium Verlag, 1959.

VALCÁRCEL, L. Etnohistoria del Perú antiguo. Lima: Universidad Nacional Mayor de San Marcos, 1943. 